\title{
Effect of Ticagrerol versus Clopidogrel on Inflammatory Bio-marker in Patients with Chronic Stable Angina Patients after Percutaneous Coronary Intervention
} ELORA SHARMIN ${ }^{1}$, JASMINE FAUZIA DEWAN ${ }^{2}$, SYED ALI AHASAN ${ }^{1}$, SHEIKH FOYEZ AHMED
PRITHA PULOMA $^{1}$,

${ }^{1}$ Department of Cardiology, Bangabandhu Sheikh Mujib Medical University, Dhaka, ${ }^{2}$ Department of Pharmacology, Bangabandhu Sheikh Mujib Medical University, Dhaka, ${ }^{3}$ Master stuudent of Biochemistry, Uppsala University,Sweden,

${ }^{4}$ Department of Oncology, Rajshahi Medical College.

Address for correspondance: Dr Elora Sharmin, Medical officer, Department of Cardiology, Bangabandhu Sheikh Mujib Medical University, Dhaka.Email: eloradoc@gmail.com

\begin{abstract}
:
Background: Ischemic heart disease remains the leading cause of death in both developed and under developed countries. The use of antiplatelet drugs specifically the thienopyridine has become a standard for the treatment of acute coronary syndrome. These drugs irreversibly inhibit the platelet aggregation by blocking the P2Y12 receptor. But currently this therapeutic choice has become limited due to potential interaction with other drugs, slow hepatic conversion, genetic resistance and narrow therapeutic safety margin. Ticagrerol, a reversible P2Y12 receptor inhibitor may represent a significant advancement over currently available oral antiplatelet drugs. Objectives: The study was intended to compare the effect of Ticagrelor and Clopidogrel on inflammatory and oxidative stress markers in patients of chronic stable angina (CSA) following percutaneous coronary intervention (PCI). Materials \& Methods: The present prospective observational study was carried out in the Department of Pharmacology, Cardiology and Microbiology, BSMMU, Dhaka from September 2014 to February 2016. The study included a total of 100 CSA patients. Patients were divided into two groups, Ticagrelor and Clopidogrel treated groups (each having 50 patients). The baseline laboratory parametersHigh sensitive C-reactive protein (hs-CRP), bleeding time, clotting time, were measured and then patients of both groups underwent PCI. The same parameters were again assessed at follow up after 4 weeks of intervention. Total 12 patients from Ticagrelor and 14 patients from Clopidogrel groups were dropped out. Comparisons of the laboratory parameters were made between two groups at baseline and at follow up and also within group before and after intervention. Result: In the present study at baseline characteristics of patients treated with Ticagrelor and Clopidogrel were almost identical in terms of age, sex, diabetes and hypertension. The inflammatory marker hs-CRP was also similar in both groups at baseline. At follow up hs-CRP was significantly reduced from baseline $19.7 \mathrm{mg} / \mathrm{dl}$ to $1.7 \mathrm{mg} / \mathrm{dl}$ (p value- 0.001 ) in ticagrerol group and $18.4 \mathrm{mg} / \mathrm{dl}$ to $2 \mathrm{mg} / \mathrm{dl}$ (p value-0.001) in clopidogrel group. There was no significant change in bleeding time and clotting time in both groups of patients. Conclusion: The study concluded that both Ticagrelor and Clopidogrel are similar in improving the status of the inflammatory marker, resulting from inflammatory processes in patients of chronic stable angina.
\end{abstract}

Introduction:

Coronary heart disease is a major global health problem in European country ${ }^{1}$. Low and middle income countries, including South Asian countries like India and Pakistan, contribute significantly to the global burden of cardiovascular disease. A projection made by Murray and Lopez (1997) showed that by 2020, 78\% of all deaths and $86.3 \%$ of all loss of disability adjusted life years (DALYs) will be attributable to this cause $\mathrm{e}^{2,10}$.

Atherosclerotic process as well as inflammatory process undergoing in the coronary arteries may lead to angina pectoris, myocardial infraction (MI) and if untreated may lead to death. The damage due to athero-thrombotic inception and oxidative stress in such conditions plays pivotal role in the progression of the disease ${ }^{3}$. High sensitive C-reactive protein (hs-CRP), TNFá and IL-6 are sensitive markers of inflammation ${ }^{4}$ and malondialdehyde and reduced glutathione are sensitive markers of oxidative stress $^{5}$.The hs-CRP exerts a direct role in the expression of cell adhesion molecule, this protein thus may be of great prognostic value as well as those of the oxidants evolved during stressful condition ${ }^{6}$.There is a powerful predictive association between raised serum high sensitive C-reactive protein (hsCRP) values and the outcome of 
acute coronary syndrome (ACS) ${ }^{4}$. Baseline values of hsCRP are indicative of metabolic state associated with athero-thrombotic events. The presence of hs-CRP within most athero-thrombotic plaque suggests that it may contribute to the pathogenesis and complication of cardiovascular disease $\mathrm{f}^{7,8,9}$. High sensitive C-reactive protein (hs-CRP) binds to lipoprotein and activates proinflammatory complement ${ }^{7,8,9}$.

Ticagrelor, a comparatively recently introduced ADPreceptor inhibitor, is a member of the theienopyridine class of adenosine diphosphate (ADP) receptor inhibitors which reduces platelet aggregation by reversibly binding to ADP receptors on platelet membrane ${ }^{7,8,9}$. Compared to clopidogrel and prasugrel, ticagrelor inhibit adenosine diphosphate (ADP) induced platelet aggregation more rapidly and more consistently to a greater extent both in the healthy subjects and in patients with coronary artery disease including those undergoing percutaneous coronary intervention (PCI) ${ }^{11}$ and reduce the risk of death either resulting from vascular cause, myocardial infraction (MI) or stroke ${ }^{12}$.

In acute coronary syndrome (ACS) inflammatory processes play active role leading to formation of atheroma. So if the antiplatelet drugs could exert anti-inflammatory effect, might be beneficial for the prevention of morbidity and mortality from cardiovascular diseases ${ }^{13}$.

In patients of ACS following PCI, the chance of thrombotic phenomenon is increased because of inflammatory reaction. In that situation an antiplatelet drug having antiinflammatory action could be a better option. Therefore the present study has been designed to compare the antiinflammatory properties of ticagrelor and clopidogrel in CSA patients following PCI.

\section{Discussion and results:}

Coronary artery disease is the major cause of mortality and morbidity worldwide ${ }^{14}$. Inflammation is a key etiological factor in the development of atherosclerotic disease and acute coronary syndromes (ACS) ${ }^{4,15,16}$. Many inflammatory biomarkers have been studied as both prognostic indicators and possible intervention targets. Among these are the inflammatory biomarkers interleukin 6 (IL 6), High sensitive C-reactive protein (hs-CRP), myeloperoxidase (MPO), and soluble CD40 ligand (sCD40L), which represent pathophysiological steps in the inflammatory prosses that may contribute to the pathogenesis of ACS ${ }^{17}$. Ticagrelor and Clopidogrel both groups were almost identical in terms of their demographic characteristics (age and sex).The clinical characteristics (diabetes and hypertension) were also identically distributed between groups. The inflammatory marker high sensitive C-reactive protein was almost similar between the study groups. As most of the baseline characteristics were almost similar in distribution between groups, the outcome obtained could be considered due to intervention drugs.

Inflammation plays a role in the development of atherosclerosis and coronary heart disease ${ }^{18}$.Elevated markers of inflammation, particularly high sensitive CRP are associated with increased risk of cardiovascular events 19,21, 22, 23. Previously, the clinical benefits of antiplatelet therapy with the P2Y12 receptor inhibitor clopidogrel in ACS patients compared with placebo by reducing the cardiovascular deaths and nonfatal MI or stroke ${ }^{20}$. treatment with ticagrelor, the first revesrsibly binding oral P2Y12 receptor inhibitor, result s in greater inhibition of platelet aggregation than clopidogrel in patients with satable atheseclerotic disease or ACS ${ }^{789}$.Some studied suggest that an anti-inflammatory effect may contribute to the clinical efficacy of P2Y12 inhibitor.In this study we observed that hs-CRP was higher in CSA patients in baseline. After treatment the hs CRP was reduced from baseline to follow-up in ticagrerol group $19.7 \mathrm{mg} / \mathrm{dl}$ to 1.7 $\mathrm{mg} / \mathrm{dl}$ (p value- 0.001 ) and in clopidogrel group $18.4 \mathrm{mg} / \mathrm{dl}$ to $2 \mathrm{mg} / \mathrm{dl}$ (p value- 0.001 ).

After 4 weeks of intervention, both groups showed significant reduction hsCRP indicating that antiinflammatory effect takes place in patients of CSA. However, summarizing the findings of the study, it is evident that both the antiplatelet drugs are effective in improving the status inflammatory marker but ticagrelor seems to be better than the clopidogrel.

\section{Conclusion:}

From the findings of the study, it appears that both ticagrelor and clopidogrel are effective in improving the status of inflammatory marker resulting from inflammatory process caused by chronic stable angina. But in terms of outcome, ticagrelor could be considered better than the clopidogrel.

\section{References:}

1. Levi F, Lucchini F, Negri E, and La Veenchia C. Trends in mortality from cardiovascular and cerebrovascular disease in Europe and other areas of the world. Heart British Medical Journal, 2002; vol. 88, no. 2, pp.119-24.

2. Murray CJ, Lopez AD.Mortality by cause for eight regions of the world: Global Burden of Disease study.1997; Lancet, vol. 349, pp. 1269-76. 
3. Libby F, Rider PM.Novel inflammatory markers of coronary risk. Circulation, 1999; vol. 1100, pp. 1148-50.

4. Ridker PM.Inflammatory biomarkers and risks of myocardial infarction, stroke, diabetes, and total mortality: implications for longevity.Nutrision Revised, 2007;vol. 65, pp. S253-S259.

5. Aparna P, Betigeri MA, Pasupathi P.Homocysteine and oxidative stress markers and inflammation in patients with coronary artery disease.International Journal of Biological and Medical Research, 2010;vol. 1, no.4, pp. 125- 29

6. Moukarbel GV, Arnout MS, Alam SE.C-reactive protein is a marker for a complex culprit lesion anatomy in unstable angina.Clinical Cardiology, 2001; vol. 24, no. 7, pp. 506-10.

7. Husted S, Emanuelsson H, Heptinstall S, Sandset PM, Wickens M, Peters G. Pharmacodynamics, pharmacokinetics, and safety of the oral reversible P2Y12 antagonist AZD6140 with aspirin in patients with atherosclerosis: a double-blind comparison to clopidogrel with aspirin.European Heart Journal, 2006; vol. 27, pp. 1038- 47.

8. Husted S, Van Giezen JJ. Ticagrelor: the first reversibly binding oral P2Y12 receptor antagonist. Cardiovascular Therapeutics, 2009; vol. 27, no. 4, pp. 259-74.

9. Husted S, Storey RF, Harrington RA, Emanuelsson H, Cannon CP.Changes in Inflammatory Biomarkers in Patients Treated with Ticagrelor or Clopidogrel.Clinical Cardiology, 2010;vol. 33, no. 4, pp. 206-12.

10. 10 .Murray C, Lopez AD. Mortality by cause for eight regions of the world: Global Burden of Disease study.Lancet, 1997 vol. 349, pp. 1269-76.

11. Birkeland K, Parra D, Rosenstein R.Antiplatelet therapy in acute coronary syndromes: focus on ticagrelor. Journal of Blood Medicine, 2010; vol. 1, pp. 197- 219.

12. Wallentin L, Becker RC, Budaj A, Cannon CP, Emanuelsson H, Held C, Horrow J, Husted S, James S, Katus H, Mahaffey KW, Scirica BM, Skene A, Steg PG, Storey RF, Harrington RA. Ticagrelor versus Clopidogrel in Patients with Acute Coronary Syndromes. New England Journal of Medicine, 2009; vol. 361, pp. 1045-57.

13. Pepys MB, Williams G.C-reactive protein and amyloidosis from protein to drug. In: Royal college of physicians of London, 1999; p. 397-414.
14. Ojha SK, Nandave M, Arora S, Narang R, Dinda AK, Arya DS. Chronic administration of Tribulus terrestris Linn. Extract improves cardiac function and attenuates myocardial infarction in rats. Int $J$ Pharmacol.2008; 4: 1-10.

15. Lucas AR, Korol R, Pepine CJ, inflammation in atherosclerosis; some thoughts about acute coronary syndromes, Circulation 2006;113:e 728- e732

16. Khuseyinova N, Koenig W, Biomarkers of outcome from cardiovascular disease, Curr Opin Crit Care, 2006;12:412419

17. Armstrong EJ, Morrow DA, Sabatine MS. inflammatory biomarkers in acute coronary syndromes, part I: introduction and cytokines.Circulation, 2006; vol. 113, pp. 72-75.

18. Lind L. Circulating markers of inflammation and atherosclerosis.Atherosclerosis. 2003; 169(2): 203-214.

19. Zairis MN, Manousakis SJ, Stefanidis AS, Papadaki OA, Andrikopouaos GK, Olympios CD, Hadjissavas JJ, Argyrakis SK, Foussas SG. C-reactive protein levels and prognosis after ST-segment elevation acute myocardial infarction. Am Heart J. 2002; 144(5): 782-789.

20. Yusuf S, Zhao F, Mehta SR, et al; for the Clopidogrel in Unstable Angina to Prevent Recurrent Event Trial Investigators. Effect s of clopidogrel in addition to aspirin in patients with acute coronary syndromes without ST-segment elevation. $N$ Engl J Med.345:494-502

21. Azar, R.R, Kassab, R., Zoghbi, A., Aboujaoude, S., Ghorra, P., Germanos , M., Salame, E., Hazem E, C. , 2006, 'Effects of clopidogrel on soluble CD40 ligand and on high-sensitivity Creactive protein in patients with stable coronary artery disease', American Heart Journal , vol. 151, pp. 521.1521.e 4 .

22. Chen, Y.G., Xu, F., Zhang, Y., Ji, Q.S., Sun, Y., Lü, R.J., Li, R.J., 2006, 'Effect of aspirin plus clopidogrel on inflammatory markers in patients with non-ST-segment elevation acute coronary syndrome', Chinese Medical Journal, vol. 119, pp. 32-36.

23. Woodward M, Lwe GD, Francis LM, et al. A randomized comparison of the effects of aspirin and clopidogrel on thrombotic risk factor and C-reactive protein following myocardial infraction :the CADET trial . J Thromb Haemost. 2004;2:1934-1940 